\title{
Optimisation of growth hormone production by muscle cells using plasmid DNA
}

\author{
G S MacColl ${ }^{1,2}$, F J Novo ${ }^{2}$, N J Marshall ${ }^{3}$, M Waters ${ }^{4}$, \\ G Goldspink ${ }^{2}$ and P M G Bouloux ${ }^{1}$ \\ ${ }^{1}$ Department of Medicine, Royal Free and University College Medical School, London, UK \\ ${ }^{2}$ Department of Anatomy and Developmental Biology, Royal Free and University College Medical School, London, UK \\ ${ }^{3}$ Molecular Pathology and Clinical Biochemistry, Royal Free and University College Medical School, London, UK \\ ${ }^{4}$ Physiology and Pharmacology Department and Centre for Molecular and Cellular Biology, University of Queensland, St Lucia, Queensland, Australia \\ (Requests for offprints should be addressed to G MacColl, Centre for Neuroendocrinology, Department of Medicine, Royal Free and University College \\ Medical School, Rowland Hill Street, London NW3 2PF, UK; Email: gmaccoll@rfc.ucl.ac.uk)
}

\begin{abstract}
The production of peptide hormones by skeletal muscle tissue is a promising area of gene therapy. Skeletal muscle myogenesis can be induced in vitro, resulting in the fusion of mononucleate myoblasts to form multinucleate myotubes, and delivery vectors are first tested in vitro. C2C12 myoblasts transfected with pcDNA3-GH, which used the human cytomegalovirus (CMV) promoter, secreted immunoreactive $\mathrm{GH}$ with comparable biological activity to pituitary GH. Mouse myeloid leukaemia cells, which express the mouse $\mathrm{GH}$ receptor were used for the bioassay, and activation of these cells by GH was measured by a colorimetric microculture tetrazolium assay. Cells were incubated with a tetrazolium salt (MTS) and an intermediate electron acceptor (phenazine methosulphate, PMS), and formazan production was measured as optical density (O.D.) at $490 \mathrm{~nm}$.

The efficiencies of several plasmid expression vectors were compared in differentiated and non-differentiated muscle cells, as a function of bioactive $\mathrm{GH}$ secreted by the transfected cells. Ten-day differentiated C2C12 myotubes transfected with pcDNA3E-GH, which used the CMV promoter and a rat myosin light chain enhancer element,
\end{abstract}

secreted significantly more biologically active $\mathrm{GH}$ than myotubes transfected with pcDNA3-GH (0.82 O.D. units \pm 0.06 vs $0.57 \pm 0.05$ respectively, $P<0.001)$. This was consistent with reduced CMV promoter activity in myotubes. Myoblasts transfected with pcDNA3-GH secreted more bioactive GH than 10-day transfected myotubes $(1 \cdot 1 \pm 0 \cdot 1$ vs $0 \cdot 77 \pm 0 \cdot 07$ respectively). However, the responses were indistinguishable (both $1 \cdot 0 \pm 0 \cdot 09)$ if both the myotubes and myoblasts had been transfected with pcDNA3E-GH. Substitution of the vector pMHLC-GH, which used a muscle-specific truncated rabbit myosin heavy chain promoter, and the myosin enhancer resulted in a marked decrease in the responses to the conditioned medium from fused myotubes compared with the vectors pcDNA3-GH and pcDNA3E-GH $(0 \cdot 24 \pm 0.02$ vs $0.57 \pm 0.05$ vs $0.82 \pm 0.06$ respectively). We concluded that the combination of CMV promoter and myosin light chain enhancer in pcDNA3E-GH had the greatest expression efficiency of the several plasmid vectors which we investigated.

Journal of Endocrinology (2000) 165, 329-336

\section{Introduction}

Gene transfer into skeletal muscle is currently being developed as a method for producing proteins with potential therapeutic benefits, and a wide variety of applications have been envisaged, including treatment for muscular dystrophy (Floyd et al. 1997), motor neurone diseases (Haase et al. 1996) and peripheral vascular disease (Takeshita et al. 1994). There have been some promising results from clinical trials using muscle gene transfer as an instrument of therapeutic drug delivery. For instance, significant clinical improvements were observed in a recent phase 1 clinical trial, where plasmid DNA encoding vascular endothelial growth factor had been injected into the limb muscles of patients with critical limb ischaemia. New collateral blood vessel growth, improved distal blood flow and healing of ischaemic ulcers were observed, resulting in successful limb salvage in 3 patients recommended for below-knee amputation (Baumgartner et al. 1998).

Recent studies have shown that skeletal muscle can be adapted for use as an artificial endocrine tissue (reviewed in MacColl et al. 1999), and this methodology has been used to produce physiologically active leptin (Murphy et al. 1997) and erythropoietin (Tripathy et al. 1994). Additionally, gene transfer into muscle has been used to 
1.

\begin{tabular}{|l|l|l|l|l|}
\hline pCMV & RGH cDNA & pA & ColE1 & Amp \\
\hline
\end{tabular}

2.

\begin{tabular}{|l|l|l|l|l|l|}
\hline pCMV & RGH cDNA & pA & ColE1 & Amp & MLCE \\
\hline
\end{tabular}

3.

\begin{tabular}{|l|l|l|l|l|l|}
\hline pMHC & RGH cDNA & pA & ColE1 & Amp & MLCE \\
\hline
\end{tabular}

Figure 1 Plasmid vectors used to produce recombinant $\mathrm{GH}$ in C2C12 myoblasts and myotubes. 1, pcDNA3-GH; 2, pcDNA3E$\mathrm{GH} ; 3, \mathrm{pMHLC}-\mathrm{GH}$. The construction of each vector is described in the Materials and Methods section and the relevant sequences are shown here (not to scale): human cytomegalovirus immediate early promoter ( $\mathrm{pCMV}$ ), rabbit myosin heavy chain promoter (pHMC), rat myosin light chain enhancer (MLCE), rat growth hormone complementary DNA (RGH CDNA), bovine growth hormone polyadenylation signal $(\mathrm{pA}), E$. coli origin of replication (ColE1), ampicillin resistance gene (Amp).

produce the key hormones and growth factors which regulate growth. These include growth hormone releasing hormone (Draghia-Akli et al. 1998), growth hormone (Barr \& Leiden 1991, Dahler et al. 1994, Anwer et al. 1998) and insulin-like growth factor-I (Barton-Davis et al. 1998).

Skeletal muscle consists of different types of multinucleated fibres, originating from myoblast stem cells which fuse during the embryonic development of muscle tissue (myogenesis). In postnatal life, the self-renewal and growth of differentiated muscle tissue is further mediated by a resident population of mononuclear myogenic precursors, the satellite cells. In response to muscle injury, satellite cells divide and fuse to repair or replace damaged fibres (Ferrari et al. 1998). The bulk of muscle cells in developed muscle tissue are, however, non dividing and gene delivery vectors are stably maintained in post-mitotic muscle fibres following intramuscular injection. This provides muscle with a considerable advantage over other tissues used for the production and secretion of therapeutic proteins, as a long-term release of protein can be achieved following gene transfer in vivo (Tripathy et al. 1996).

Myogenic differentiation can also be manipulated in culture, as myoblasts can be induced to differentiate in vitro. By replacing the culture medium with serumdeficient fusion media, a clear morphological change from dividing myoblasts to quiescent multinucleated myotubes occurs after several days. This allows gene transfer vectors such as plasmid DNA molecules to be tested in differentiated muscle cells in vitro, before advancing to in vivo studies (Dahler et al. 1994, Novo et al. 1997).

Here, we have tested several plasmid DNA vectors encoding rat growth hormone, in transfected, cultured rodent muscle cells. The plasmid vectors used for these studies contained viral or muscle-specific promoters, or a combination of both types (Fig. 1), and murine C2C12 myoblasts (Blau et al. 1985) were used to analyse each plasmid transfect in vitro. Initially, the bioactivity of recombinant rat growth hormone produced by transfected C2C12 myoblasts was compared with pituitary-derived rat growth hormone $(\mathrm{GH})$, using a somatogenic bioassay. The target cells used for this bioassay were mouse myeloid leukaemia cells, which were producing the murine growth hormone receptor (Rowlinson et al. 1996). A microculture tetrazolium assay (MTA) was used to measure activation of myeloid cells by growth hormone (described by Goodwin et al. 1996). The bioassay was used to compare the amounts of recombinant rat GH produced by undifferentiated myoblasts and by differentiated myotubes, as a function of each plasmid transfection (MacColl et al. 1998).

\section{Materials and Methods}

\section{Synthesis of rat $G H c D N A$}

Materials Total pituitary tumour RNA was provided by Dr D Flavell, Division of Neurophysiology, National Institute of Medical Research, London, UK. The first strand cDNA synthesis kit was supplied by Clontech Laboratories UK Ltd (Basingstoke, UK) and Taq DNA polymerase by Life Technologies Ltd (Paisley, UK). Polymerase chain reaction (PCR) oligonucleotides were synthesised by Oswell DNA Service, Southampton, UK. Electrophoresis grade agarose and ethidium bromide were supplied by Sigma-Aldrich Company Ltd (Gillingham, UK).

\section{Reverse transcription (RT)-PCR}

A rat growth hormone complementary DNA (GH cDNA) was made from total rat pituitary RNA by RT-PCR. First strand cDNA was primed with an oligomeric dT primer and synthesised using avian myeloblastosis virus (AMV) reverse transcriptase, according to the manufacturer's instructions. PCR oligonucleotides were based on the published GH cDNA sequence (Seeburg et al. 1977) and each PCR amplimer contained an SalI restriction endonuclease site (underlined) to facilitate cloning of the PCR product in each of the three expression vectors used in these studies. The PCR oligonucleotides were designed to make a product containing the entire open reading frame and the $3^{\prime}$ untranslated region (UTR) of the GH cDNA. A 5' UTR was provided by each of the $\mathrm{GH}$ expression vectors. The primers used were:

forward 5': CCGTCGACATGGCTGCAGACTCTCA GACTCCC and

reverse 3': CCGTCGACATTAGGACAAAGTGTAGG GGTGGC.

PCR amplification of the cDNA was carried out with a Techne thermal cycler, using Taq DNA polymerase 
according to the manufacturer's instructions. The conditions used for the PCR were $95{ }^{\circ} \mathrm{C}$ for $1 \mathrm{~min}$, followed by 30 cycles of $95^{\circ} \mathrm{C}$ for $1 \mathrm{~min}, 56^{\circ} \mathrm{C}$ for $1 \mathrm{~min}, 72^{\circ} \mathrm{C}$ for $1 \mathrm{~min}$, and then $72{ }^{\circ} \mathrm{C}$ for $5 \mathrm{~min}$. Five percent of the PCR reaction was run on a $0.7 \% \mathrm{w} / \mathrm{v}$ agarose gel, and a product of approximately 730 base pairs was visualised by staining the gel with ethidium bromide, as described in Sambrook et al. (1989). The remainder of the solution containing the PCR product was purified through a silica-gel membrane (Qiagen Ltd, UK, Crawley, UK).

\section{GH vector construction}

Materials Sall, XhoI, BamHI and BglII restriction endonucleases and T4 DNA ligase were supplied from Boehringer Mannheim UK Ltd (Lewes, UK). The plasmid pcDNA3 was supplied from Invitrogen (Groningen, Netherlands). Subcloning efficiency competent DH5 $\alpha$ cells were supplied by Life Technologies Ltd.

Methods Five micrograms of the PCR product were enzymatically digested for $24 \mathrm{~h}$ with 100 units SalI restriction endonuclease, and purified as described above. To make pMHLC-GH (Fig. 1), the 729 base pair product containing the GH cDNA was ligated into p $\beta$ PASe9 (Miller et al. 1995), which had previously been digested with SalI. This vector contains a truncated rabbit myosin heavy chain beta cardiac promoter (Cribbs et al. 1989), and a rat myosin light chain enhancer (Donoghue et al. 1988), both of which have specific activity in differentiated muscle cells. The second vector, pcDNA3-GH, used a human cytomegalovirus (CMV) immediate early promoter to drive $\mathrm{GH}$ expression in muscle cells (Fig. 1). pcDNA3-GH was made by removing the GH cDNA from pMHLC-GH by SalI restriction digest, and by ligating to pcDNA3 digested with Xhol. The third vector, pcDNA3E-GH (Fig. 1), was made in two steps: first, the 920 base pair sequence containing the myosin light chain enhancer was removed from p $\beta$ PASe9, using BamHI restriction endonuclease, and this was ligated into pcDNA3 digested with BglII to make pcDNA3E. Secondly, the 729 bp SalI DNA fragment containing the $\mathrm{GH}$ cDNA was ligated to pcDNA3E, which had been digested with XhoI, to make pcDNA3E-GH.

T4 DNA ligase was used for all DNA ligations, according to the manufacturer's instructions. Competent DH5 $\alpha$ $E$. coli cells were used to screen ligation reactions for recombinant DNA vectors, as described by Sambrook et al. (1989). Plasmid DNA, used for sequencing and muscle cell transfections, was prepared from transformed $\mathrm{DH} 5 \alpha$ cells by alkaline lysis and anion exchange chromatography, using a Maxi prep kit (Qiagen Ltd UK) and following the manufacturer's instructions. The PCR product was sequenced for insert orientation and for open reading frame fidelity using the method described by Sanger et al. (1977), with a Sequenase version $2 \cdot 0$ kit (Amersham-Pharmacia Ltd).

In vitro muscle cell culture and transfections

Materials $\mathrm{C} 2 \mathrm{C} 12$ myoblasts were obtained from the American Tissue Culture Collection (ATCC-CRL-1772; ATCC, Rockville, MD, USA); lipofectamine, fetal bovine serum (FBS), horse serum (HS), phosphate buffered saline (PBS), Optimem, and Dulbecco's modified Eagle's medium (DMEM) with glutamax were obtained from Life Technologies Ltd (Paisley, Strathclyde, UK). Corning $75 \mathrm{~cm}^{2}$ vented flasks, 6 well tissue culture plates, Gentamycin and Ampicillin from Sigma Aldrich Ltd.

\section{C2C12 myoblast and myotube cultures}

Frozen C2C12 mouse myoblasts (Blau et al. 1985), were thawed rapidly at $37^{\circ} \mathrm{C}$, transferred into $15 \mathrm{ml}$ growth medium (DMEM+glutamax containing 10\% FBS and $0.5 \%$ gentamycin/ampicillin) in a $75-\mathrm{cm}^{2}$ vented flask, and medium was changed once the cells had adhered. Myoblasts were routinely grown to between $70-80 \%$ confluence, and split 1:20 every 2 days. Myoblasts were induced to fuse into myotubes by replacing growth medium with fusion medium, where 5\% HS was used as the serum supplement, and fresh medium was added every 2 days. Differentiation of cells was established visually, as myoblast fusion into myotubule-like syncytia (Barnhart et al. 1998). Cells were incubated in a humidified atmosphere of $5 \% \mathrm{CO}_{2} / 95 \%$ air at $37{ }^{\circ} \mathrm{C}$.

\section{Transfection of C2C12 myoblasts}

A modified version of the method described by Trivedi and Dickson (1995) was used to transfect C2C12 myoblasts. Initially, a mixture of cationic liposome (lipofectamine) and a plasmid containing the chloramphenicol acetyl transferase (CAT) reporter gene (pcDNA3-CAT) was used to optimise the transfection of C2C12 myoblasts. Cells were lysed for $24 \mathrm{~h}$ after transfection and assayed for CAT activity following the method described by Gorman et al. (1982). This optimised method was used to transfect myoblasts with each of the GH expression plasmids. Dividing myoblasts were seeded in 6-well dishes $(2 \mathrm{ml})$ at a final density of $7 \cdot 5 \times 10^{4} \mathrm{cells} / \mathrm{ml}$, and grown for $18 \mathrm{~h}$. Lipofectamine $(10 \mu \mathrm{g})$ and plasmid DNA $(2 \mu \mathrm{g})$ were mixed together in $1 \mathrm{ml}$ serum-free medium (Optimem), and incubated for $45 \mathrm{~min}$ at room temperature. Cultures were washed 3 times in PBS to remove serum, and overlaid with lipofectamine/DNA complexes. Each transfection was incubated in $5 \% \mathrm{CO}_{2} / 95 \%$ air at $37^{\circ} \mathrm{C}$ for $5 \mathrm{~h}$, and stopped by adding fusion medium. Transfected myoblasts were either grown for $48 \mathrm{~h}$ before analysis of rat 
growth hormone production, or left over a 10-day period to reach confluence and to differentiate into myotubes.

\section{Western blot for recombinant rat GH}

Materials Affinity-purified rat GH and primary antibody to rat GH (rhesus anti-rat growth hormone, RGH-IC1) were obtained from the National Hormone and Pituitary Program (NHPP, Harbour-UCLA Medical Center, Torrance, CA, USA), USA. Microconcentrators with a $5 \mathrm{kDa}$ molecular mass cutoff were obtained from Vivascience, Lincoln, UK Ltd and prestained molecular weight markers were obtained from New England Biolabs Inc., Hitchin, UK. All electrophoresis reagents, Tween-20, rabbit anti-monkey $\operatorname{IgG}$ alkaline phosphatase conjugate, EDTA, and 5-bromo-4-chloro-3-indoloyl phosphate (BCIP) and nitro blue tetrazolium (NBT) developing reagent were obtained from Sigma-Aldrich; Hybond-C nitrocellulose membrane was purchased from Amersham-Pharmacia Biotech Ltd, St Albans, UK.

\section{Western transfer and detection of rat GH}

Forty-eight hours after transfection, conditioned medium $(500 \mu \mathrm{l})$ was removed from myoblasts, transferred to a microconcentrator and centrifuged at $13000 \mathrm{~g}$ for $15 \mathrm{~min}$. Cell lysates were prepared as described by Novo et al. (1997), and concentrated. Protein concentrates from each transfection were separated under reducing conditions by SDS-polyacrylamide gel electrophoresis (SDS-PAGE), as described in Sambrook et al. (1989). Protein molecular weight markers, rat growth hormone standard and protein concentrates were denatured at $80{ }^{\circ} \mathrm{C}$ for $10 \mathrm{~min}$ in $1 \times$ sample loading buffer, and loaded onto a discontinuous polyacrylamide gel with a $4 \%$ acrylamide stacking gel and a $12 \%$ resolving gel. Each gel was run for $1 \mathrm{~h}$ with a constant current of $60 \mathrm{~mA}$ per gel.

Protein was transferred to Hybond-C membranes using the method described in Harlow and Lane (1988). Membranes were washed once in PBS and incubated overnight at $4{ }^{\circ} \mathrm{C}$ in blocking solution: PBS containing $5 \% \mathrm{w} / \mathrm{v}$ fat free milk powder (Marvel), and $0.01 \% \mathrm{v} / \mathrm{v}$ Tween 20 . Membranes were incubated at $4{ }^{\circ} \mathrm{C}$ for $2 \mathrm{~h}$ with primary antibody (RGH-IC1) diluted 1 in 200 in blocking solution, and then washed 3 times in PBS containing 0.01\% v/v Tween 20. Second antibody (rabbit anti-monkey IgG alkaline phosphatase conjugate) was diluted 1 in 2000 in blocking solution, and incubated with membranes at room temperature for $1 \mathrm{~h}$. Membranes were then washed 3 times in $0.01 \%$ Tween 20 in Tris-buffered saline ( $\mathrm{pH} 8$ ). Alkaline phosphatase activity was detected by incubating nitrocellulose membranes with $5 \mathrm{ml}$ developing reagent, containing BCIP and NBT. Reactions were stopped by adding 20 mM EDTA, pH 8.

\section{Somatogenic bioassay for rat $\mathrm{GH}$}

Materials The creation of murine myeloid leukaemia cells that stably express the murine growth hormone receptor (FDCP1-MGHR) has been described previously (Rowlinson et al. 1996). RPMI-1640 was obtained from Life Technologies Inc. Penicillin, streptomycin, L-glutamine, Corning $25 \mathrm{~cm}^{2}$ tissue culture flasks and 96 well microculture dishes were obtained from SigmaAldrich Company Ltd. Human pituitary growth hormone (hGH - IS 80/505) was provided by the National Institute for Biological Standards and Control (South Mimms, Herts, UK). 5-(3-carboxymethoxyphenyl)-2-(4,5-dimethylthiazolyl)-3-(4-sulphophenyl) tetrazolium inner salt (MTS) and phenazine methosulphate (PMS) were obtained from Promega UK Ltd (Southampton, UK).

Cell culture FDCP1-MGHR cells were maintained in suspension culture, in $25-\mathrm{cm}^{2}$ flasks with growth medium consisting of RPMI-1640 medium without phenol red containing 10\% FBS, $100 \mathrm{U}$ penicillin/ml, $100 \mu \mathrm{g}$ streptomycin $/ \mathrm{ml}, 2 \mathrm{mM}$ L-glutamine and $0 \cdot 1 \mu \mathrm{g} / \mathrm{ml}$ human growth hormone. Myeloid cells were routinely passaged every 3 days, and cultures were incubated in a humidified atmosphere of $5 \% \mathrm{CO}_{2} / 95 \%$ air at $37^{\circ} \mathrm{C}$.

\section{Microculture tetrazolium assays}

A microculture tetrazolium assay (MTA) was used to measure the metabolic activation of FDCP1-MGHR cells by growth hormone. Cells were resuspended in assay medium without hGH, with $10 \%$ HS used as the serum supplement. Cells were dispensed into 96-well microculture dishes $(50 \mu \mathrm{l})$ at a final density of $8 \times 10^{5}$ cells $/ \mathrm{ml}$ and activated with $50 \mu \mathrm{l}$ aliquots of assay medium containing either recombinant rat $\mathrm{GH}$ derived from transfected muscle cells, or known amounts of pituitary-derived rat GH. For the comparison between recombinant rat growth hormone and pituitary standard, conditioned media from three separate transfections, shown by Western blot to contain immunoreactive GH, were pooled and serially diluted in assay medium before adding to FDCP1-MGHR cells. Assay plates were then incubated for $24 \mathrm{~h}$ in a humidified, gassed chamber at $37^{\circ} \mathrm{C}$.

MTS tetrazolium salt and PMS, an intermediate electron acceptor, were used for the colorimetric MTA (Goodwin et al. 1996). Twenty microlitres of a solution containing an optimised mixture of MTS+PMS $(4 \cdot 1 \mathrm{mM}$ MTS +0.15 mM PMS) were added to assay wells and mixed. Each assay plate was then incubated in a dry, non-gassed incubator at $37^{\circ} \mathrm{C}$ for $2 \mathrm{~h}$. The quantity of soluble formazan produced by bioreduction of MTS was determined by measuring optical density (O.D.) at $490 \mathrm{~nm}$. Each sample was assayed in triplicate, and O.D. values expressed as the mean \pm s.E.M. Significant 


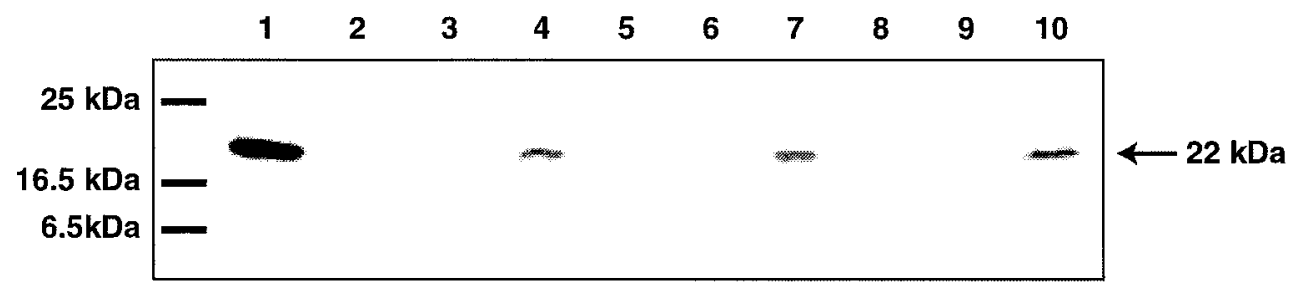

Figure 2 Western blot of recombinant growth hormone produced by transfected C2C12 myoblasts. Conditioned medium was removed from undifferentiated C2C12 myoblasts 2 days after transfection with either pcDNA3 or pcDNA3-GH. Three independent transfections were analysed and immunoreactive recombinant rat $\mathrm{GH}$ was detected using $\mathrm{RGH}-\mathrm{IC} 1$ antisera, as described in the Materials and Methods section. Each replicate transfection is shown. Lane 1, $50 \mathrm{ng}$ rat pituitary $\mathrm{GH}$ standard; lanes 2, 5, 8, conditioned media from C2C12 myobolasts transfected with pcDNA3; lanes 3, 6, 9, cell extracts from C2C12 myoblasts transfected with pcDNA3-GH; lanes 4, 7, 10, conditioned media from C2C12 myoblasts transfected with pcDNA3-GH.

differences between mean O.D. values were determined using a Student's $t$-test, with significance set as $P \leq 0 \cdot 05$.

\section{Results}

\section{Immunoreactivity of rat GH produced by C2C12 myoblasts}

Undifferentiated C2C12 myoblasts produced immunoreactive recombinant rat growth hormone 2 days after transfection with pcDNA3-GH, and Fig. 2 shows a Western blot of conditioned media from 3 separate transfections. These contained recombinant protein which co-migrated at $22 \mathrm{kDa}$ with pituitary-derived rat growth hormone. A more sensitive method of chemiluminescent detection also demonstrated that rat GH was also present in cell extracts (data not shown). Rat GH immunoreactivity could not be detected using these methods, either in control C2C12 myoblasts or in cells transfected with plasmid without the GH cDNA (pcDNA3).

\section{Bioactivity of recombinant rat $G H$}

The conditioned media from $\mathrm{C} 2 \mathrm{C} 12$ myoblasts transfected with pcDNA3-GH stimulated FDCP1-MGHR myeloid cells, which express the murine GH receptor, as measured by the MTA assay (Fig. 3). Hormonal specificity of these responses to the pooled media was demonstrated by the abolition of the bioactivity by preincubation with an

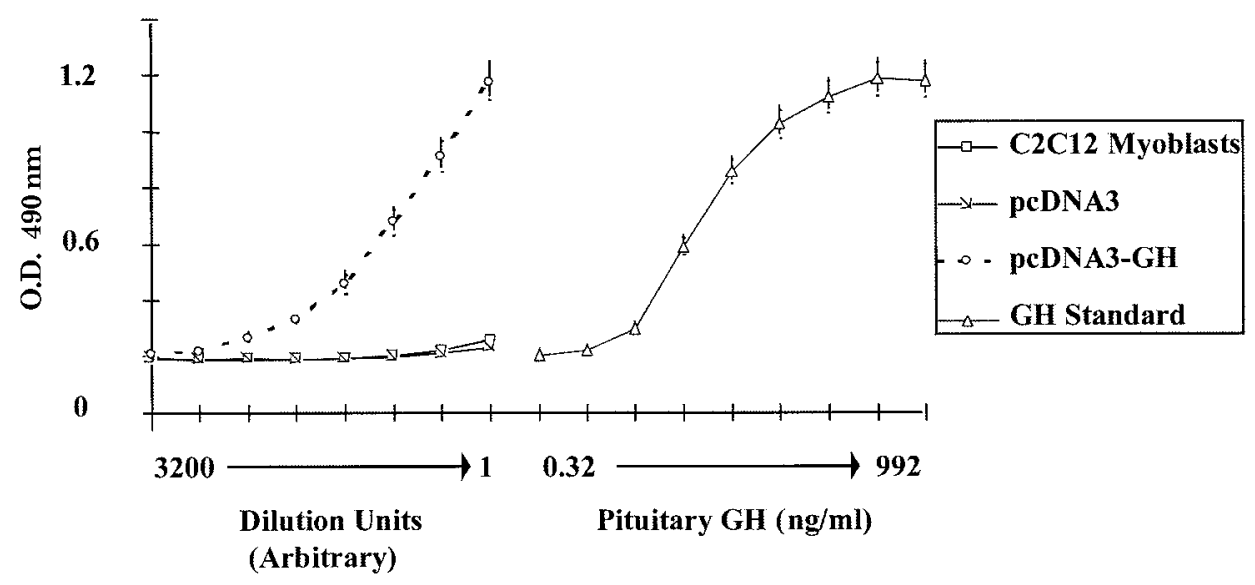

Figure 3 Stimulation of FDCP1-MGHR cells by rat GH produced by transfected C2C12 myoblasts. Conditioned media, containing immunoreactive rat $\mathrm{GH}$ from 3 separate transfections of $\mathrm{C} 2 \mathrm{C} 12$ myoblasts, were pooled and assayed for somatogenic activity. Serial dilutions of pooled media, taken from undifferentiated myoblasts $48 \mathrm{~h}$ after transfection with pcDNA3-GH, were used to activate target cells in the colorimetric somatogenic bioassay, as described in the Materials and Methods section. Hormonal activation was quantified by the increased O.D. $(490 \mathrm{~nm})$ due to formazan production by FDCP1-MGHR target cells. Negative controls were run as described in the text. In addition, a doseresponse curve to affinity purified rat pituitary $\mathrm{GH}$ standard was run in parallel in this bioassay. For both $\mathrm{GH}$ preparations, each dilution was tested in replicate wells $(n=3)$ and all responses are expressed as mean O.D. \pm S.E.M. 

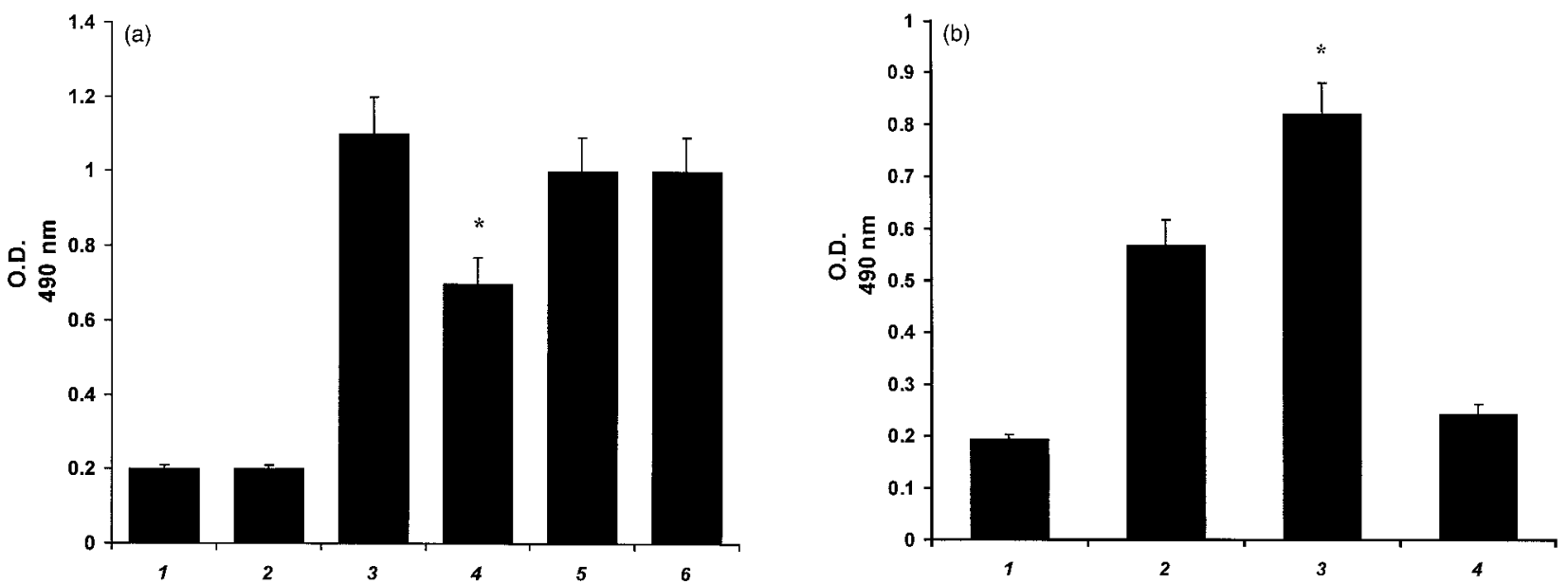

Figure 4 (a) Comparison between plasmid vector activities in undifferentiated C2C12 myoblasts, and in differentiated C2C12 myotubes. Conditioned media were harvested from cultures of undifferentiated C2C12 myoblasts 2 days after transfection, or from differentiated $\mathrm{C} 2 \mathrm{C} 12$ myotubes 10 days after transfection, and tested for rat $\mathrm{GH}$ production using the somatogenic bioassay. The transfection variants were: 1, untransfected myotubes; 2, myotubes transfected with pcDNA3; 3, myoblasts transfected with pcDNA3-GH; 4, myotubes transfected with pcDNA3-GH; 5, myoblasts transfected with pcDNA3E-GH; 6, myotubes transfected with pcDNA3E-GH. Transfected myoblasts were induced to differentiate into myotubes, as described in the Materials and Methods section. Transfections were repeated three times and the conditioned media from individual experiments were assayed for GH bioactivity in replicate wells $(n=3)$. All responses are expressed as mean O.D. \pm S.E.M., ${ }^{*} P<0 \cdot 001$ for variant 4 compared with variant 3 . (b) Comparison between 3 plasmid expression vectors in 10-day cultures of transfected C2C12 myotubes. The transfection variants were: 1, untransfected myotubes; 2 myotubes transfected with pcDNA3-GH; 3, myotubes transfected with pcDNA3E-GH; 4, myotubes transfected with pMHLC-GH. Transfected myoblasts were induced to differentiate into myotubes as described in the Materials and Methods section. For each plasmid, conditioned medium from 6 separate transfections was tested for rat GH bioactivity in replicate cultures of FDCP1-MGHR target cells $(n=3)$ and all responses are expressed as mean O.D. \pm S.E.M. ${ }^{*} P<0 \cdot 001$ for variant 3 compared with variant 2.

antibody raised against the native hormone (results not shown). No stimulation was observed with the media harvested from negative controls of untransfected C2C12 myoblasts, or from cells that had been transfected with pcDNA3 only. A comparison between dose-response curves to the secreted recombinant rat GH and rat pituitary-derived GH standard, revealed essentially parallel response increments (Fig. 3).

\section{Comparison of vector efficiency in muscle cells}

The bioassay was used to compare the levels of recombinant rat GH secreted into conditioned medium by undifferentiated C2C12 myoblasts and fused myotubes, which had been transfected with plasmid GH expression vectors containing different combinations of viral and muscle promoter elements (Fig. $4 \mathrm{a}$ and b). Figure 4a shows the comparison of CMV promoter activity in both cell types. Ten days after transfection with pcDNA3-GH, the bioassay response to the rat $\mathrm{GH}$ secreted from differentiated myotubes was significantly less than that secreted from undifferentiated myoblasts (0.77 O.D. units \pm 0.07 vs $1 \cdot 1 \pm 0 \cdot 1$ respectively, $P<0 \cdot 001)$. These responses were indistinguishable (both $1 \cdot 0 \pm 0 \cdot 09$ ) if myotubes and myoblasts were instead transfected with pcDNA3E-GH, which included both the CMV promoter and the myosin light chain enhancer element (Fig. 4a).
In a separate series of transfections, we compared the efficiencies of different plasmids in 10-day cultures of transfected C2C12 myotubes. We confirmed that when myotubes had been transfected with pcDNA3E-GH they produced significantly more $\mathrm{GH}$ than myotubes transfected with pcDNA3-GH $(0.82 \pm 0.06$ vs $0.57 \pm 0.05$, $P<0 \cdot 001)$ (Fig. 4b). However, if the plasmid vector pMHLC-GH was substituted, there was a marked decrease in the responses to the conditioned medium from fused myotubes, compared with pcDNA3-GH and pcDNA3E-GH $(0.24 \pm 0.02$ vs $0.57 \pm 0.05$ vs $0.82 \pm$ 0.06 respectively) (Fig. 4b). This vector contained the myosin heavy chain promoter and myosin light chain enhancer element. We concluded that, since the responses observed were a direct function of the GH secreted, the combination of CMV promoter and myosin light chain enhancer in pcDNA3E-GH had the greatest expression efficiency of the vectors which we investigated.

\section{Discussion}

The aim of this study was to compare the relative amounts of recombinant rat $\mathrm{GH}$ produced by three types of plasmid DNA vector in differentiated C2C12 myotubes and in undifferentiated $\mathrm{C} 2 \mathrm{C} 12$ myoblasts, with a view to developing one or more of these for delivering GH in vivo. 
Immunoreactive recombinant rat $\mathrm{GH}$ was secreted by C2C12 myoblasts transfected with pcDNA3-GH, and this had the same molecular weight as pituitary-derived rat $\mathrm{GH}$. The somatogenic bioassay was then used to demonstrate that the immunoreactive protein had a comparable biological activity to native rat $\mathrm{GH}$. Both recombinant and pituitary-derived $\mathrm{GH}$ generated similar dose-response curves over the same dilution range, when incubated with FDCP1-MGHR cells.

Using this bioassay to measure $\mathrm{GH}$ secretion as a function of promoter activity, the efficiency of the CMV promoter was then compared in both transfected C2C12 myoblasts and differentiated myotubes. We found that myotubes transfected with pcDNA3-GH produced significantly less biologically active GH when compared with myoblasts transfected with the same construct. However, when the CMV promoter was combined with a musclespecific enhancer in the vector pcDNA3E-GH, equivalent levels of bioactive $\mathrm{GH}$ were secreted by transfected C2C12 cells irrespective of the state of differentiation of these muscle cells.

The decrease in the levels of GH secreted, following differentiation of transfected myoblasts into myotubes, and the subsequent attenuation of this effect when the CMV promoter was combined with the myosin light chain enhancer element in pcDNA3E-GH, was consistent with our current understanding of several of the cellular processes that control gene expression during myogenesis. First, the reduction in GH secretion observed in myotubes transfected with pcDNA3-GH may have been caused by the decrease in binding activity of the activator protein-1 (AP-1) transcriptional activator, which occurs following the induction of myogenesis in vitro (Lehtinen et al. 1996). AP-1 is a heterodimer consisting of Fos and Jun protein monomers, which specifically activates promoters that contain the binding site TGACTCA, including the CMV promoter used in pcDNA3-GH and pcDNA3E-GH (Lehtinen et al. 1996).

The difference between the levels of GH secreted by myotubes transfected with pcDNA3-GH, as opposed to pcDNA3E-GH must be due to the myosin light chain enhancer. This enhancer is activated specifically in differentiated C2C12 myotubes, but not in dividing myoblasts (Donoghue et al. 1988), as it contains several E box (CANNTG) and $\mathrm{A} / \mathrm{T}$ rich $(\mathrm{CTA}) \mathrm{A} / \mathrm{T}_{4}$ ) DNA motifs. These sites bind to the myogenic differentiation factor (MDF) and myocyte enhancer families of transcription factors, which are expressed during muscle cell differentiation (Neville \& Rosenthal 1996). The observations indicate that the myosin light chain enhancer compensates for the reduction in CMV promoter activity, which occurs following differentiation of transfected muscle cells.

In comparison with the plasmids using the CMV promoter, pMHLC-GH generated much lower levels of $\mathrm{GH}$ in transfected C2C12 myotubes. This vector used a truncated myosin heavy chain promoter in combination with the myosin light chain enhancer element, and the results were consistent with previous observations where these vectors were used for the expression of human alpha-galactosidase (Novo et al. 1997). However, we have also shown that the promoter elements used in pMHLC-GH generate tissue-specific gene expression in muscle fibres (Skarli et al. 1998) and as other studies show that specific types of muscle promoters are effective at producing hormones in muscle cells (Barton-Davis et al. 1998, Li et al. 1999), this vector is being studied further.

In conclusion, the amount of biologically active growth hormone produced by transfected $\mathrm{C} 2 \mathrm{C} 12$ myotubes was found to depend on the types of promoter element used in each plasmid vector, and a combination of viral and muscle-specific transcription elements proved to be the most effective. However, it is also recognised that plasmid vectors which are effective in cultured muscle cells, may not be as potent when used for gene transfer into skeletal muscle (Barnhart et al. 1998), and therefore these conclusions may not apply to in vivo situations.

\section{Acknowledgements}

The authors would like to thank Drs D Gorecki (Department of Clinical Genetics) and M Skarli (Department of Anatomy and Developmental Biology, Royal Free and University College Medical School Hospital, School of Medicine) for helpful comments on the manuscript. G M was supported by Pharmacia and Upjohn.

\section{References}

Anwer K, Shi M, French MF, Muller SR, Chen W, Liu QS, Proctor BL, Wang JJ, Mumper RJ, Singhal A, Rolland AP \& Alila HW 1998 Systemic effect of human growth hormone after intramuscular injection of a single dose of a muscle-specific gene medicine. Human Gene Therapy 9 659-670.

Barnhart KM, Hartikka J, Manthorpe M, Norman J \& Hobart P 1998 Enhancer and promoter chimeras in plasmids designed for intramuscular injection: a comparative in vivo and in vitro study. Human Gene Therapy 9 2545-2553.

Barr E \& Leiden JM 1991 Systemic delivery of recombinant proteins by genetically modified myoblasts. Science 254 1507-1509.

Barton-Davis ER, Shoturma DI, Musaro A, Rosenthal N \& Sweeney HL 1998 Viral mediated expression of insulin-like growth factor-I blocks the aging-related loss of skeletal muscle function. Proceedings of the National Academy of Sciences of the USA 95 15603-15607.

Baumgartner I, Pieczek A, Manor O, Blair R, Kearney M, Walsh K \& Isner JM 1998 Constitutive expression of phVEGF(165) after intramuscular gene transfer promotes collateral vessel development in patients with critical limb ischemia. Circulation 97 1114-1123.

Blau HM, Pavlath GK, Hardeman EC, Chiu CP, Silberstein L, Webster SG, Miller SC \& Webster C 1985 Plasticity of the differentiated state. Science 230 758-766.

Cribbs LL, Shimizu N, Yockey CE, Levin JE, Jakovcic S, Zak R \& Umeda PK 1989 Muscle-specific regulation of a transfected rabbit myosin heavy chain beta gene promoter. Journal of Biological Chemistry 264 10672-10678. 
Dahler A, Wade RP, Muscat GEO \& Waters MJ 1994 Expression vectors encoding human growth hormone $(\mathrm{hGH})$ controlled by human muscle-specific promoters - prospects for regulated production of hGH delivered by myoblast transfer or intravenous injection. Gene 145 305-310.

Donoghue M, Ernst H, Wentworth B, Nadal-Ginard B \& Rosenthal N 1988 A muscle-specific enhancer is located at the $3^{\prime}$ end of the myosin light-chain 1/3 gene locus. Genes and Development 2 1779-1790.

Draghia-Akli R, Li XY \& Schwartz RJ 1998 Enhanced growth by ectopic expression of growth hormone releasing hormone using an injectable myogenic vector. Nature Biotechnology 15 1285-1289.

Ferrari G, Cusella DeAngelis G, Coletta M, Paolucci E, Stornaiuolo A, Cossu G \& Mavilio F 1998 Muscle regeneration by bone marrow derived myogenic progenitors Science 279 1528-1530.

Floyd SS, Booth DK, van Deukekom JCT, Day CS \& Huard J 1997 Autologous myoblast transfer: a combination of myoblast transplantation and gene therapy. Basic and Applied Myology 7 241-250.

Goodwin CJ, Holt SJ, Downes S \& Marshall NJ 1996 The use of intermediate electron-acceptors to enhance MTT bioreduction in a microculture tetrazolium assay for human growth hormone. Life Sciences 59 1745-1753.

Gorman CM, Moffat LF \& Howard BH 1982 Recombinant genomes which express chloramphenicol acetyl transferase in mammalian cells. Molecular Cell Biology 2 1044-1051.

Haase G, Kennel P, Vigne E, Akli S, Revah F, Schmalbruch H \& Kahn A 1996 Gene therapy of murine motor neuron disease using adenoviral vectors for neurotrophic factors. Nature Medicine $\mathbf{3}$ 429-436.

Harlow E \& Lane D 1988 Antibodies, A Laboratory Manual. New York: Cold Spring Harbour Laboratory Press.

Lehtinen SK, Rahkila P, Helenius M, Korhonen P \& Salminen A 1996 Down-regulation of transcription factors AP-1, SP-1, and NF-kappa-B precedes myocyte differentiation. Biochemical and Biophysical Research Communications 229 36-43.

Li XY, Eastman EM, Schwartz RJ \& Draghia-Akli R 1999 Synthetic muscle promoters: activities exceeding naturally occurring regulatory sequences. Nature Biotechnology 17 241-245.

MacColl G, Novo J, Marshall N, Goldspink G \& Bouloux P 1998 A method for producing biologically active growth hormone in muscle cells. Journal of Endocrinology (Suppl) 156 OC 20.

MacColl G, Goldspink G \& Bouloux P 1999 Using skeletal muscle as an artificial endocrine tissue. Journal of Endocrinology 162 1-9.

Miller G, Steinbrecher RA, Murdock PJ, Tuddenham EGD, Lee CA, Pasi KJ \& Goldspink G 1995 Expression of factor VII by muscle cells in vitro and in vivo following direct gene transfer: modelling gene therapy for haemophilia. Gene Therapy 2 736-742.

Murphy JE, Zhou SZ, Giese K, Williams LT, Escobedo JA \& Dwarki VJ 1997 Long-term correction of obesity and diabetes in genetically obese mice by a single intramuscular injection of recombinant adeno-associated virus encoding mouse leptin. Proceedings of the National Academy of Sciences of the USA 94 13921-13926.

Neville C \& Rosenthal N 1996 Transcriptional regulation of skeletal myogenesis. In Eukaryotic Gene Transcription, edn 1, pp 192-233. Ed S Goodbourn. Oxford: IRL Press.

Novo FJ, Gorecki DC, Goldspink G \& MacDermot KD 1997 Gene transfer and expression of human alpha-galactosidase from mouse muscle in vitro and in vivo. Gene Therapy 4 488-492.

Rowlinson SW, Waters MJ, Lewis UJ \& Barnard R 1996 Human growth-hormone fragments 1-43 and 44-191 - in vivo somatogenic activity and receptor-binding characteristics in human and nonprimate systems. Endocrinology 137 90-95.

Sambrook J, Fritsch EF \& Maniatis T 1989 Molecular Cloning: A Laboratory Manual. New York: Cold Spring Harbour Laboratory Press.

Sanger F, Nicklen S \& Coulson AR 1977 DNA sequencing with chain-terminating inhibitors. Proceedings of the National Academy of Sciences of the USA 74 5463-5467.

Seeburg PH, Shine J, Martial JA, Baxter JD \& Goodman HM 1977 Nucleotide sequence and amplification in bacteria of structural gene for rat growth hormone. Nature 270 486-494.

Skarli M, Kiri A, Vrbova G, Lee CA \& Goldspink G 1998 Myosin regulatory elements as vectors for gene transfer by intramuscular injection. Gene Therapy 5 514-520.

Takeshita S, Pu LQ, Stein LA, Sniderman AD, Bunting S, Ferrara N, Isner JM \& Symes JF 1994 Intramuscular administration of vascular endothelial growth factor induces dose-dependent collateral artery augmentation in a rabbit model of limb ischaemia. Circulation $\mathbf{9 0}$ 228-243.

Tripathy SK, Goldwasser E, Lu MM, Barr E \& Leiden JM 1994 Stable delivery of physiological levels of recombinant erythropoietin to the systemic circulation by intramuscular injection of replicationdeficient adenovirus. Proceedings of the National Academy of Sciences of the USA 91 11557-11561.

Tripathy SK, Svensson EC, Black HB, Goldwasser E, Margalith M, Hobart PM \& Leiden JM 1996 Long-term expression of erythropoietin in the systemic circulation of mice after intramuscular injection of a plasmid DNA vector. Proceedings of the National Academy of Sciences of the USA 93 10876-10880.

Trivedi RA \& Dickson G 1995 Liposome-mediated gene-transfer into normal and dystrophin-deficient mouse myoblasts. Journal of Neurochemistry 64 2230-2238.

Received 17 May 1999

Revised manuscript received 16 December 1999 Accepted 11 January 2000 